\title{
البيئة اللغوية العربية في تعليم اللغة العربية لغير الناطقين بها
}

\author{
مبرورة \\ جامعة دار السلام كونتور
}

Email: cerialulu@gmail.com

\begin{abstract}
ملخص
إن اللغة العربية من اللغات التي انتشر تعليمها في شتى بلاد العالم. وكان تعليمها ليس من أمر بسيط بل يحتاج إلى بذل جهد عظيم من قبل المعلم والمتعلم. ولا سيما إذا جاء المعلم أو الدارسين من غير الناطقين باللغة العربية. فهذا الأمر يكون التحدي العظيم نهو مدرسي اللغة العربية. ووجود البيئة اللغوية العربية تكون المساعدة التي تدور دورا هاما في تعليمها وفي إبراز ونمو المهارات اللغوية الأربعة.

إن هذه البيئة اللغوية العربية تأتي من نوعين، وهي البيئة اللغوية العربية الرسمية وغير الرسمية. كل من هاتين تقوم على وظيفتها في تعليم اللغة العربية داخل أو خارج الفصل. لأن كل الموجودة حول دارسي اللغة العربية من السمعية والبصرية تساعد على إبحاح هذا التعليم. ومن الضروري الاهتمام الكبير في البيئة اللغوية العربية وما فيها من المساعدات في تعليم اللغة العربية لغير الناطقين بها.

الكلمة الرئيسية: تعليم اللغة العربية، البيئة اللغوية العربية، البيئة الرسمية وغير الرسمية

\section{Abstrak}

Bahasa Arab merupakan bahasa yang dipelajari diberbagai belahan dunia. Pembelajaran bahasa Arab sendiri bukanlah merupakan suatu yang mudah. Namun dibutuhkan kerja keras dari berbagai pihak, entah dari pihak guru atau pun pelajar. Apalagi jika pelajar Bahasa Arab sendiri bukan dari pembicara bahasa asli. Tentu hal ini merupakan sebuah tantangan yang berat bagi seorang guru pengajar bahasa Arab. Dengan adanya lingkungan bahasa Arab akan sangat membantu pembelajaran bahasa Arab bagi pembicara non asli, baik dalam pembelajarannya sendiri atau pun dalam peningkatan kemampuan berbahasa yang standar dengan empat standar kemampuan bahasa.
\end{abstract}


Lingkungan bahasa Arab sendiri terdiri dari dua macam, yaitu lingkungan bahasa Arab resmi dan lingkungan bahasa Arab non resmi. Setiap dari kedua lingkungan bahasa arab tersebut sangat berperan penting dalam pembelajaran bahasa Arab baik di dalam maupun di luar kelas. Karena segala yang ada disekitar pelajar, baik yang berifat audio atau pun visual akan sangat berpengaruh dalam kesuksesan pembelajaran bahasa Arab. Maka sangat pentinglah bagi kita untuk mengetahui apa itu lingkungan bahasa Arab dan perannya yang dapat membantu pembelajaran bahasa Arab bagi pembicara non asli.

Kata Kunci: Pembelajaran Bahasa Arab, Lingkungan Bahasa Arab, Lingkungan Resmi dan non Resmi

المقدمة

اللغة هي تعبير مدهش عن قدرة الله سبحانه وتعالى التي لا تتناهى، فنواة هي

صوت الإنسان وأعضاؤه النطقية، والصوت مساحته محدودة، وإمكانات أعضاء النطق

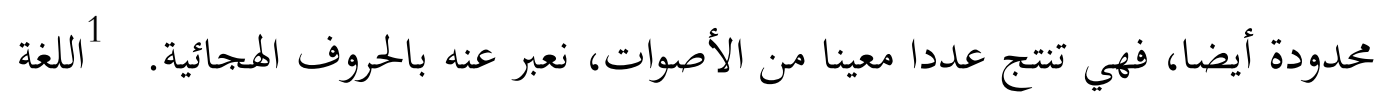
كائن حي، مثل الكائنات الحية الأخرى. وهي تتأرجح بين الحياة والموت، وتعيش قوية أو ضعيفة أو مهددة، تصارع من أجل البقاء والنماء والفاعلية الوظيفية، والابتعاد عن التقهقر والانكماش والانقراض. 2

أن اللغة ليست غريزة في الإنسان، فالطفل يولد دون لغة، ثم يبدأ في تلقي الأصوات بأذنيه، ويربط بين الصوت والشخص، وبين الصوت والشيء، وبين الصوت والحركة، ويدرك العلاقات بين الأشياء، وهكذا تتكون مفرداته، وقاموسه اللغوي. واللغة ليست شيئا جامدا، وإغتا هي نظام متحرك متظور، فعلى المستوى الفردي بند أن لغة الفرد تتطور وتتحسن مع تقدم العمر وازدياد الخبرات، وعلى المستوى الاجتماعية بحد الأمة الحية المتطورة. إنّ اللغة عنوان أهلها، فهي تحيا بحياقم، وتموت بموتهم، وتتقدم وتتطور بتقدمهم وتطورهم، وتضعف وتتخلف بضعفهم وتخلفهم.

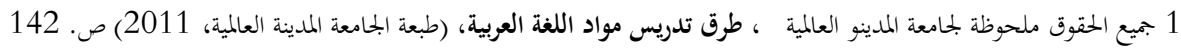

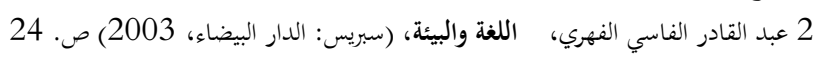


وكانت اللغة العربية إحدى من اللغة الرسمية عند اتحاد الشعوب المستخدم أكثر

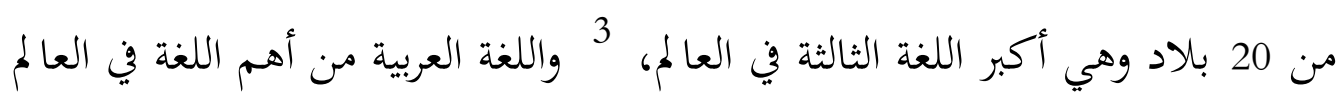
التي استخدمتها الأمهم الإسلامية حديثهم وتخاطبهم اليومية بجانب اللغة الإبحليزية. وهي كذلك أهم مقومات الثقافة العربية الإسلامية. وهي أكثر اللغات الإنسانية ارتباطا بعقيدة الأمة وهويتها وشخصيتها، وبهذه اللغة قامت الحضارة الإسلامية في العالم. لأهنا من لغة القرآن التي يجتاجها كل مسلم ليقرأ أو يفهمه الذي يستمد منه المسلم ما فهى لفي وأمر الله في شريعة الإسالام. 5

اللغة مكتسبة ونامية، فاللغة العربية مكتسبة ونامية كذلك. نظرا من أهمية اللغة العربية في العالم، كثير من دارسين اللغة العربية ياتي من غير الناطقين بها. وتعليم اللغة العربية لغير الناطقين بها يحتاج إلى جهد عظيم لأنه لازم أي يتعلم تلك اللغة منذ أساسها. ولإيجاد تعليم اللغة العربية الفعّال لغير الناطقين بها، يحتاج إلى وجود البيئة اللغوية العربية التي تساعد في إبحاح هذا التعليم. كما نعرف أن البيئة هي بحموعة جزئية من البنية التحتية لتكنولوجيا المعلومات تستخدم لغرض خاص. والبيئة التي تساعد في إبخاح هذا التعليم هي البيئة اللغوية العربية التي لما غرض خاص، هذا الغرض هو جعل دارسين اللغة العربية ذاكفاءة للمهارات اللغوية الأربعة. وللحصول على التصور الأوضح، حاولت الباحثة أن يعرض البيئة اللغوية العربية الفعّالة التي تساعد على إبحاح تعليم اللغة العربية لغير الناطقين بها.

3 Acep Hermawan, Metodologi Pembelajaran Bahasa Arab, (Bandung: Rosdakarya, 2011). Hal. 83.

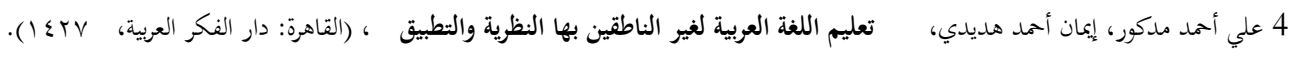

$$
5 \text { ممد علي الخولي، أساليب تدريس اللغة العربية، (الأردن: دار الفلاح للنشر والتوزيع، ... (ب)، ص. } 19 .
$$




\section{البيئة اللغوية للغة العربية}

كلمة البيئة عربية أصيلة من كلام الأجداد والأسلاف، فقد جاء في تاج العروس للزبيددي مانصه "وبوأه منزلا" نزل به إلى سند جبل.... وبوأ فيه... أنزله ومكن له فيه فأباءه إياه قال أو زيد أبات القوم منزلا وبوأقم منزلا إذا نزلت بهم إبى سند جبل أو قبل هر والايم البيئة بالكسر وبوأ المكان: حله وأقام فيه.... والمباءة أي نزل فيل ... كالبية. البيئة لفظ شائعة الاستخدام ويرتبط مدلولما بنمظ العلاقة بينها وبين مستخدمها. والبيت بيئة والمدرسة بيئة والحي بيئة والقطر بيئة والكرة بيئة والكون كله بيئة. والبيئة نفسها نوعان وهي البيئة الطبيعية والبيئة الاجتماعية. والبيئة الطبيعية تتكون من الماء والهواء والمعادن وما أشبه ذلك. وأما البيئة الاجتماعية تتكون من البنية الأساسية والبيئة المشيدة وما فيها من النظم الاجتماعية والمؤسسات التي أقامها. ومن هذا نضع معاني البيئة بعدة:

1. وأما لفظ البيئة فقد أعطاها مؤتمر ستوكهولم في عام 1972 فهما متسعا، بحيث أصبحت تدل على أكثر من بحرد عناصر طبيعية (ماء وهواء وتربة ومعادن ومصادر للطاقة ونباتات وحيوانات).... بل هي رصيد الموارد المادية والاجتماعية المتاحة في وقت ما وفي مكان ما لإشباع حاجحات الإنسان وتطلعاته.

2. والبيئة ليست بحرد موارد يتجه إليها الإنسان ليستمد منها مقومات حياته وإنما تشمل البيئة أيضا علاقة الإنسان بالإنسان التي تنظمها المؤسسات الاجتماعية والعادات والأخحلاق والقيم والأديان. 8

\footnotetext{
6 فؤاد عبد اللطيف السرطاوي، البيئة والبعد الإسلامي، (عمان: دار المسيرة، 1999) ص. 24

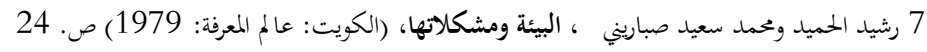

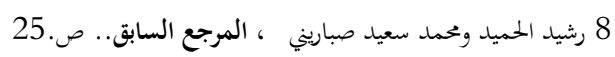


3. البيئة هي الوضع العام للإنسان في جميع شؤونه الدينية والدنيوية من سيرة وسلوك ومسكن ومأكل ومشرب وملبس وتعامل واحتاكات، غير مقصور

$$
\text { المعنى على جانب دون الآخر. }
$$

تطرح المسألة اللغوية في التعليم في كل أقطار العموم، وتقترن بها مسألة اختيار

الخطط وتوفير الظروف والآليات الملائمة للتعليم الموقف، بما فيها الظروف النفسية والبيئية التي تمكن من تعليم لغوي فاعل، لا يؤدي إلى الانفصام والاضطراب، وإفساد الأهداف المتوخاة، بما في ذلك تعطيل إنضاج الملكة اللغوية ( Linguistic competence (maturation والفكري/التفكيري، وإيصال المعارف وتوطينها، وتوطين التقانة (بما التقانة اللغوية)، والتفعيل الإجرائي والررمي، والإصهار المحتمعي للغة في محيط منسجم وموحد، لاينفي 10 التنوع.

المدرسة توفر أكبر الحظوظ الذهنية والمادية والاتصالية لإبحاح اكتساب اللغة أو اللغات، فتكون اللغة أداة فكر وتفكير، وأداة اتصال، ولغة تقانة. 11 إن حلّ مشكل ضعف مردود التعليم وضعف اللغة العربية وضعف اللغات الأنبية يمر أولا عبر هتيئ البيئة الطبيعية لتجاوز مشكل الازدواج، وتمكين المكتسب المبكر من اللغة الفصيحة، ثم عبر خلق "فضاء"ذهني عربي عموما على كل المواد، وأخيرا عبر فضاءات تعددية مندبحة ومتزنة وطبعا هناك الطرق والآلات التي تمكن من الفهم 12 والانتاج.

$$
\begin{aligned}
& 9 \text { فؤاد عبد اللطيف السرطاوي، المرجع السابق.. ص. } 25
\end{aligned}
$$

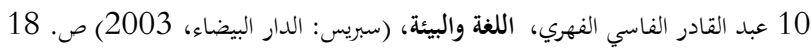

$$
\begin{aligned}
& 11 \text { عبد القادر الفاسي الفهري، المرجع السابق..ص. } 10 \\
& 12 \text { نفس المرجع، ص. } 21
\end{aligned}
$$


وأما البيئة اللغوية هي كل ما يسمع ويراه متعلم اللغة عن اللغة المكتسبة لدى متعلم اللغة. 13 و تتضمن بيئة التعلم - بالمعنى الواسع -الآراء والاتحاهات في الأسرة

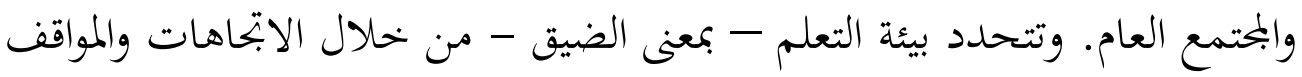
التي تحدث داخل المدرسة، حيث عملية التعليم. 14

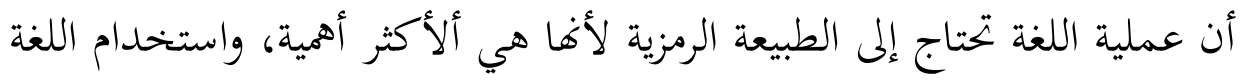

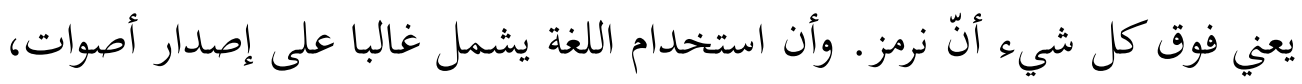

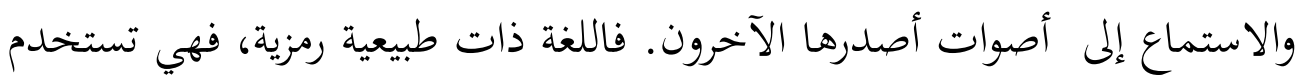

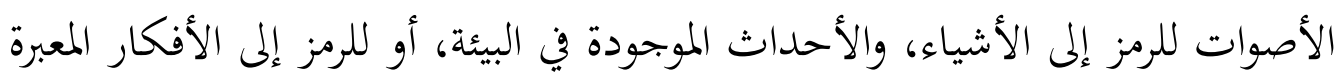

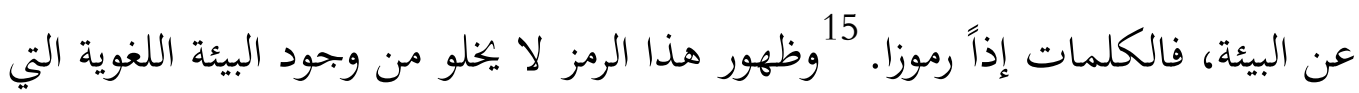
تمارس وتطور أنواع وأعداد الرموز المختلفة.

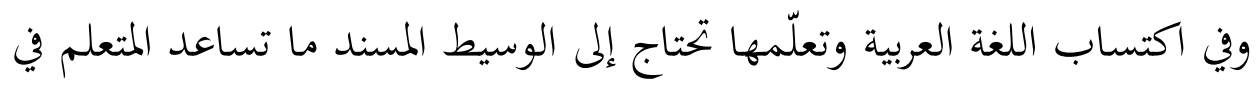

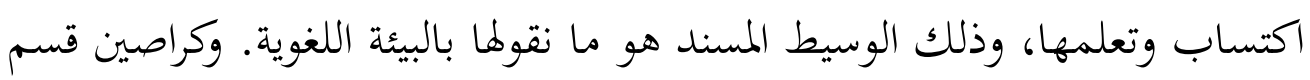
البيئة اللغوية إلى نوعين:16

1. البيئة الرسمية. وهي البيئة اللغوية ما تركز في استيعاب القواعد والنظم اللغوية

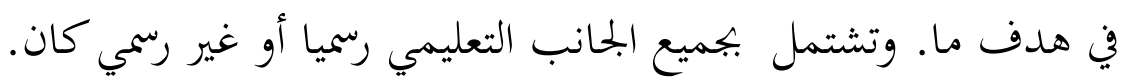

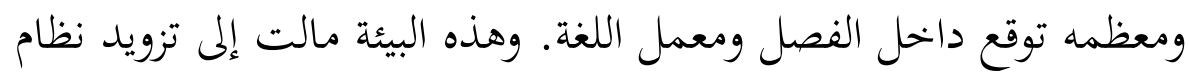
اللغة بالنسبة إلى حديثة اللغة. والبيئة الرسمية تنظم متعلم اللغة المكتسبة قادرا على استخدام اللغة ومناسبا في كل بحالها بالقواعد والتراكيب الصحيحة. وهي كذلك إحدى البيئات اللغوية التي تتركز على سيطرة القواعد أو نظام

13 Ahmad Fuad Effendy, Metodologi Pengajaran Bahasa Arab, (Malang: Misykat, 2005) cet.3 . Hlm. 165

14 رشدي أحمد طعيمة، المهارات اللغوية مستوياتها تدريسها صعوبتها، (القاهرة: دار الفكر العربي، 2004) الطبعة الأولى ، ص. 79

$$
15 \text { طرق تدريس مواد اللغة العربية، المرجع السابق، ص. صل } 143
$$

16 Ahmad Fuad Effendy, Metodologi Pengajaran Bahasa Arab..... hlm. 65 
اللغة في اللغة والهدف مع التوعية. التوعية على قواعد اللغة الهدف يمكن

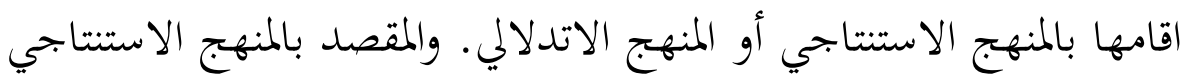
هو أن يضع المعلم للمتعلم عن قواعد اللغة الهدف ثم إن كان المتعلم فاهما ومستوعبا على القواعد فيحمل المعلم إلى التطبيق. يعني حالة لعرف

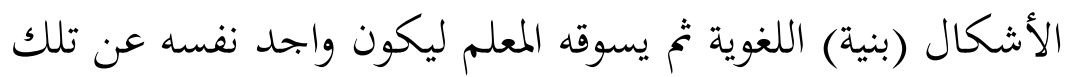

\section{القواعد.}

وليست هذه البيئة محدودة على الفصل، لأن الأهم اللغوية الثانية التي يتعلموها

من المعلم في الفصل والكتب ومن طرق أخرى خارج الفصل. ولتكون البيئة العربية

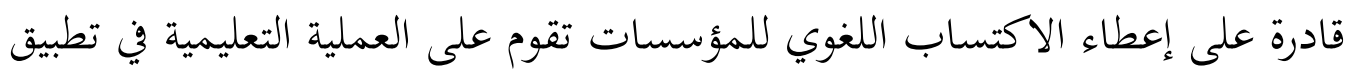

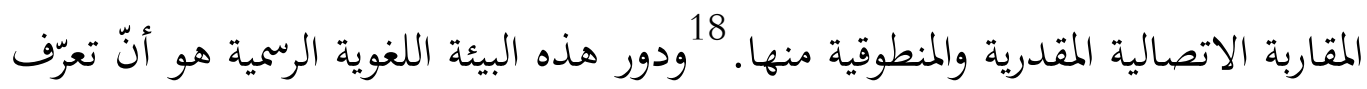
القاعدة اللغوية بالدرجات العالية لدي متعلم اللغة المكتسبة ترقي مهارقم اللغوية. 19

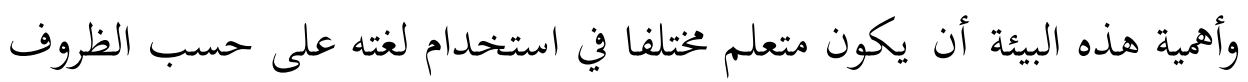

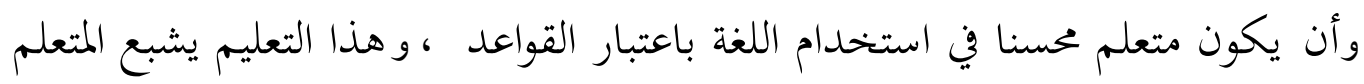

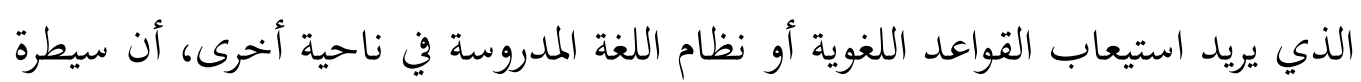

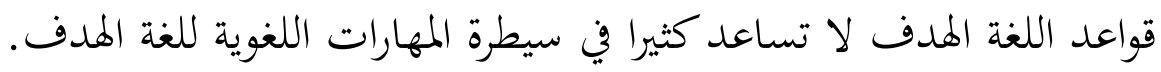
2. البيئة غير الرسمية. وهي البيئة ما تعطي استهداف الاتصال العالمي، ومعظمه

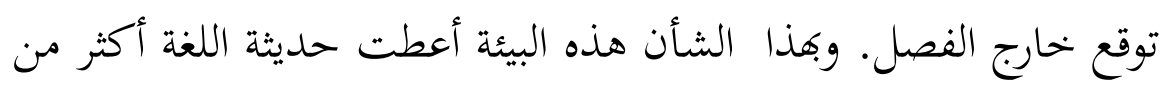
نظام اللغة. هي البيئة اللغوية التي تكون ذات أهمدات إضافية حهده لينما يكون

17 Nur Hadi, Dimensi-Dimensi Dalam Belajar Bahasa Kedua, (Bandung: Sinar Baru, 2007) hlm. 117

18 Ahmad Fuad Effendi, Metodologi Pengajaran Bahasa Arab..... hlm. 167- 168.

19 Abdul Chaer, Psikolinguistik Kajian Teoritik, Jakarta: PT Rineka Cipta, 2015), cet. 3, hlm. 259 
تركيز المتكلم على التواصل اللغوي لا على اللغة نفسها. ففي الحديث بين شخصين تكون المحادثة طبيعية، وكذلك يناسب تبادل الألفاظ بشكل طبيعي. إن المشاركين في تبادل الحديث يهتمون بتبادل المعلومات والأفكار، وفي الوقت نفسه يستعملون أبنية اللغة، ويحدث ذلك علميا دون وعي أو إدراك لبناء الجمل الذي يستعملونه.

يقصد بهذه البيئة أن استخدام اللغة بغرض التفاهم ونقل المعلومات، أي مع التركيز على المحتوى. وهذا ما منها نفعلخ عندما يتحدث متكلمي اللغة الأولى والثانية في الشارع أو الملعب. 20ومنها اللغة التي استخدمها بين الأصحاب والمربي أو الولدان وأعضاء الفيرقة التعليمية والصحافيون والأساتيذ إما في الفصل أو خارجهه. 21 تكوين البيئة اللغوية

ومن الشروط التي ينبغي بها تكوين البيئة اللغوية هي:22

1. وجود الموقف الإجابي بجاه اللغة العربية والالتزام المتين لنجاح تعليم اللغة العربية من النواحي المربوطة. وهذه النواحي هي معلم اللغة العربية ومدير الكلية نفسه.

2. وجود القدوة في بحال كلية التعليم المستخدمة باللغة العربية، إذا أمكن بحضور الناطقة الاقليمية العربية وإن ما أمكن، وجود الفريق المبتكر في بيئة التعلم. 3. وجود التسهيلات في قيام الأنشطة اللغوية العربية.

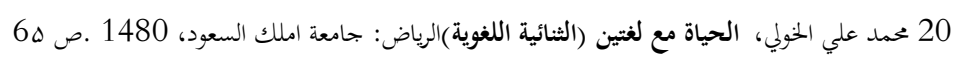

21 Abdul Chaer, Psikolinguistik Kajian Teoritik.... hlm. 260

22 Ahmad Fuad Effendy, Metodologi Pengajaran Bahasa Arab..... hlm.167 
إذا تمت الشروط في تكوين البيئة اللغوية فنجدها على الشكل الأحوال في

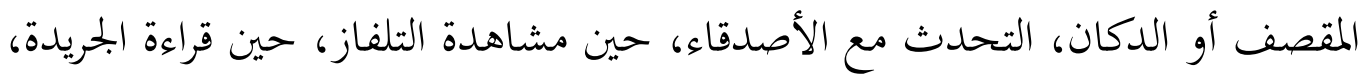
في عملية التعليم في الفصل، حين قراءة كتب الدرس وغيرها. 23 طريقة تكوين البيئة اللغوية

يرى بشيؤي أنّ تكوين البيئة اللغوية يحتاج إلى الطرق المتعددة وهي كما يلي:24

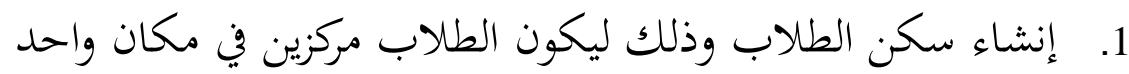
ويسهل على المشرفين والمدرسين مراعتهم وإرشادهم وإقامة أنشطة عربية مردية خارج وقت الدراسة. 2. تعيين الأماكين فيها التحدث والكلام باللغة العربية مثل المقصه ومكاتب

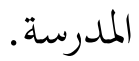
3. عقد لقاءات عربية حيث افتتاح مناقشة الأوضاع المدارسية والاجتماع والسياسية فيها بينهم على ضوء الكلمات والمفردات والمصطلحات المخفوظة والمدروسة وذلك لتدريب الطالب خارج الفصل الدراسي على صني الاستماع والتحدث والتعبير الشفهي عن انطباعاهم باللغة العربية بتحاه الأوضاع واستماع ذلك من أصحابهم.

4. إقامة دورة تعليمية للغة العربية خارج الحصة الدارسة الاصطناعية وذلك لسد ثغرات عن قلة زمن حصة العربية داخل الفصل الدراسي وذلك لتزويد

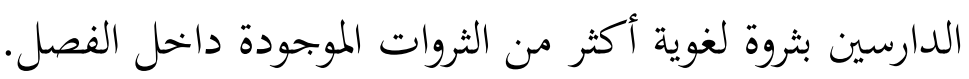

23 Abdul Chaer, Psikolinguistik Kajian Teoritik...... hlm. 258 24 بشيري ، تكوين بيئة المساعدة وتطويرها في تعليم اللغة العربية (مالانج: المقالة التي ألقاها في الدورة التدربية للمعلمين اللغة العربية جاوى بالي، 2001)، ص.14 نشئ 


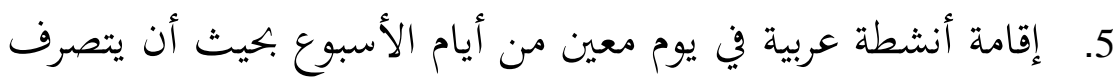

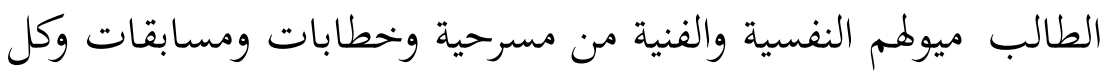

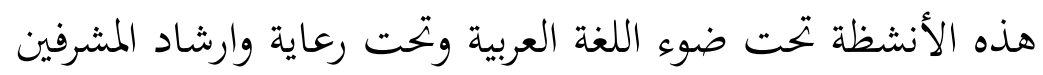
والمدرسين في اللغة العربية. 6. تدريب الطلاب على إلقاء الخطابة بالعربية في المحاضرة بعد صلاة الجماعة. 7.

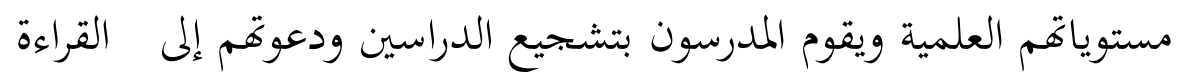
وتخصيص اوقات خاصة خارج وقت الدراسة لقراءة الكتب العربية في

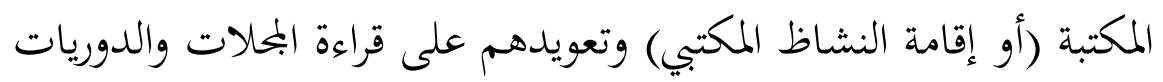
والجرائد العربية.

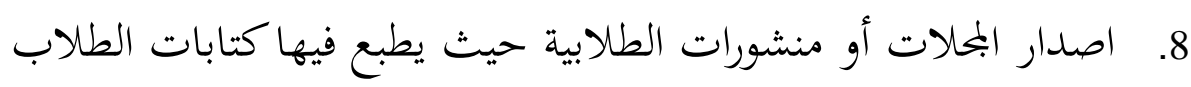

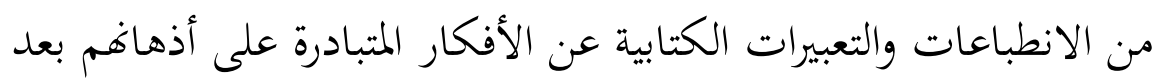
الختيار الأفضل والأحسن منها لغويا وفكريا.

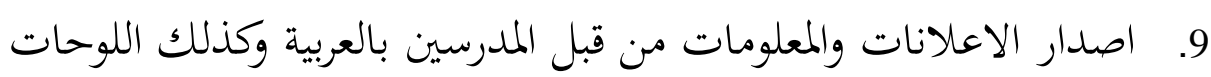

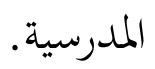

10. تعويد الطلاب على استماع ومتابعة برامج الفصحي الإذاعية ونشرات

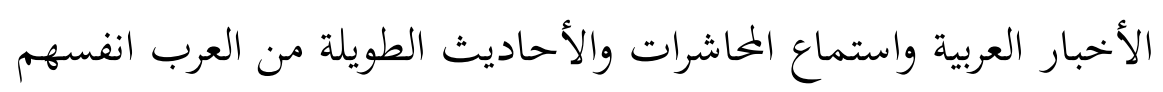

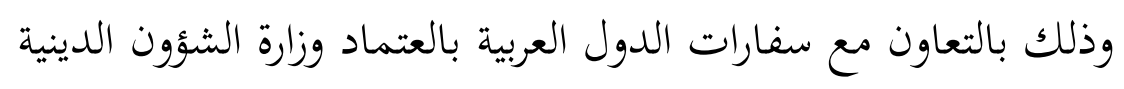
والجهاز الرسمي الآخر.

11. التعاون مع مدرسي موادالعلوم الدينية على أن تكون المواد الدينية المروسة الانتر، باللغة العربية سهلة العبارات. 12. اعطاء الثواب لمثفقي اللغة العربية والعقاب للمخلفين. 


\section{استراتيجيات البيئة اللغوية العربية}

بعد تكوين البية اللغوية يأتي معه الاستراتيجيات ما تشجع أكثر في بناح البيئة

$$
\text { نحو تعليم اللغة العربية: } 25
$$

1. الطاقة البشرية، وجود الطاقة الشرية الكافية والمتصلة باللغة العربية شفهيا أم

$$
\text { تحريريا. }
$$

2. البيئة السيكولوجية، تكوين البيئة السيكولوجية المتين في تطوير تعليم اللغة

$$
\text { العربية. }
$$

3. البيئة لتكوين المهارة الكلامية وتطويرها هي البيئة التي تستخدم اللغة العربية

$$
\text { في كل الأنشظة الكالامية كل يوم. }
$$

4. البيئة لتكوين مهارة القراءة ، فتكوينها بأمر بسيط وتأثر قويا في اكتساب اللغة العربية لدى المتعلم. ككتابة عنوان المكاتب أو المدارس باللغة العربية. 5. البيئة لتكوين مهارة الاستماع، كتكوين المعلومات اللسانية في اللغة العربية. 6. البيئة لتكوين مهارة القراءة ومهارة الاستماع، ذلك باستفادة التكنولوجي كمشاهدة البرامج العربية في التلفاز ومشاهدة الأفلام العربية.

7. الفريق المحب باللغة العربية، كتقديم اللغة العربية في الأنشطة المختلفة كحديث اليوم والتدريب للخطابة المنبرية والندوات العلمية وما أشبه ذلك. 8. إيجاد "الأسبوع العربي"، إيجاد الأنشطة اللغوية العبية المؤثرة بشتى الأشكال كالمسابقات في الخطابة المنبرية، وكتابة الإنشاء العربي والخط وقرض الشعر وما أشبه ذلك. تعليم اللغة العربية 
اللغة منهج ونظام للتفكير، والتعبير، والاتصال. وهذا يعني أها منهج للتعليم

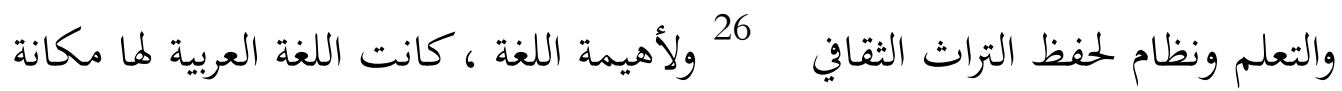
مرقومة والقدرة على استيعاب الحضارات لما تتمتع به من صفات فان. ومن الواجب أن تتضافر جهود الأمة العربية كلها لتيسير تعليمها للعرب ولغير العرب وتشجيع البحوث الخاصة بذلك وتشجيع البحوث الخاصة بذلك وتشجيع التأليف والترجمة والنشر بها وتعريب التعليم على جميع المستويات وفتح المعاهد لتعليمها للأجانب داخل البلاد العربية وخحارجها وتزويد هذه المدارس بالوسائل المعنوية على تدريسها. بجانب الاهتمام في قيام المعاهد وتأليف الكتب لتعليم اللغة العربية، وجوب الاهتمام كذلك في طريقة تعليم اللغة العربية بعد احضار تلك المؤسسة. واللغة العربية لها الطريقة في تعليمها ما يلزم الاهتمام بها، وهن: 27 1. تطور الدراسات اللغوية والدراسات التربوية في ميدان تعليم اللغة وتعلمها مما أدى إلى استحداث مناهج جديدة في دراسة اللغات وتعليمها وظهور علوم جديدة مثل علم النفس اللغوي وعلم اللغة النفسي وعلم الاجتماع اللغوي والدراسات التقابلية. وظهور مداخل جديدة لتعليم اللغة وتعلمها مثل المدخل الإيحائي، والمدخل اللغوي التكاملي، ومدخل الاستجابة الجسمية الشاملة.

2. تطور استخدام التكنولوجيا الحديثة في تعلم اللغات وظهور الحاسبات الآلية والأجهزة الصوتية والمرئية واستعمال الوسائط المتعددة في التدريس، ومما أدي إلى استحداث برامج لتعليم اللغات تعتمد على التعلم الذاتي الفردي والجماعي.

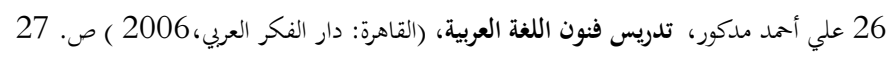

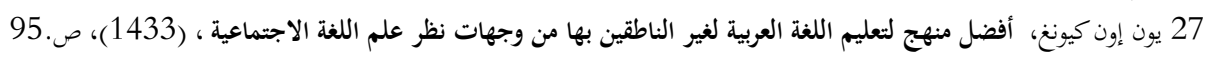


3. زيادة الاهتمام بالبحث العلمي التربوي في ميدان تعليم اللغات وتعليمها محا أدى إلى ظهور ابتحاهات جديدة في بناء المناهج والبرامج مثل البربحة والنمذجة والكفاءات، والأداء.

4. الاهتمام بالمستوى الفني للمعلم والابحاه نحو إعداد معلم اللغة العربية لغير الناطقين بها، وإنشاء العديد من المعاهد التي تقوم على إعداده وتدريبه، وإقبال معلمي هذه اللغة في أنحاء العالم المختلفة على الدورات التدريبية التي تقوم بها المنظمات العربية والإسلامية الدولية منها والمحلية لتدريب المعلمين، ومن ثم فإن بحاح أي منهج أو برنامج لتعليم العربية إنما يتوقف على مدى الاهتمام بالمستوى الفني للمعلم.

5. طبيعة وخصائص الدارسين المقبلين على تعلم اللغة العربية من الصغار والكبار، ومن مختلف الجنسيات واللغات والأغراض، فكلما توافرت لدينا دراسات ومعلومات ومعارف وبيانات حول نوعية الدارسين وخصائصهم وأعمارهم ولغاقهم ودوافعهم وخبراةم السابقة، توافرت لدينا إمكانية بناء مناهج في تعلم اللغة وبرامج مناسبة لهم، بالإضافة إلى إمكانية إعداد المواد التعليمية المناسبة لهم أيضا.

ونظرا إلى النظرية اللغوية التي تتركز على اللغة العربية وتعليمها، ولدت هذه النظرية من تدفق مذهب الإنشائية. وفقا لتدفق هذه اللغة هي:

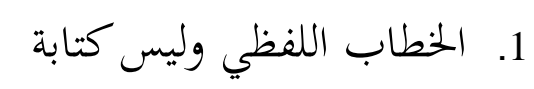
2. اكتسبت مهارات اللغة من خلال تمارين والتكرار 3. كل نظام ولغة مختلفة عن الأخرى 4. توجد لغة تمكن أن أعلنت لغات أخرى 5. أضاف أن جميع اللغات الحية وضع المفردات، الأنماط والهياكيل 
ثم تعلم اللغة العملية ستكون:

1. - 1التعود، التدريب، وتكثيف التقطيد.

2. إتقان بداية الاستماع، التحدث، القراءة والكتابة.

3. هج تعلم اللغة باستخدام التحليل التقابلي للعثور على أوجه بين الطلبة مع

اللغة من اللغة المدف (اللغة العربية).

4. الحاجة إلى أملة السرد بطلاقة بشأن الأصوات، بما فيها ينبغي أن يقرأ في

الطويلة، القصيرة، والطاقة في الهيكل حتى لا اعجاب هيكل إندونيسيا.

البيئة وتعليم اللغة العربية

ومن الطبيعي أن ينمو الطفل في بيئته الصغرى تحت إشراف غيره من الكبار:

الوالدين، والأقارب، والمعلمين، وتتمثل بيئته الكبرى في بحتمعه، ويتمثل عالمه الصغير في

مدرسته. ومن المعروف أن الطفل لديه استعداد كامل لاكتساب اللغة من بحتمع اللغة

المتمثل في هذه البيئات. وباختلاف البيئات ثراء وفقرا في اللغة والثقافة تختلف لغات

الأظفال، ويختلف مدى اكتسابهم لها. 28

علاقة اللفة بالبينة
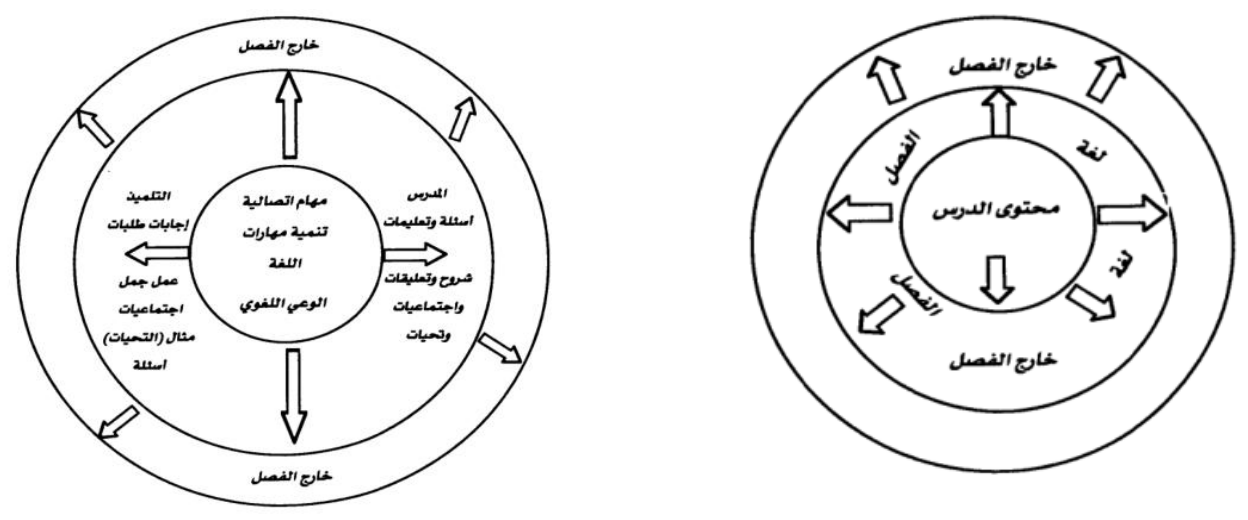

28 علي أممد مدكور، تعليم اللغة العربية....، المرجع السابق ، ص. 80

El-Ibtikar Vol 7 No 2 Desember 2018, 1-17 
يتضح من الرسم التخطيطي، أن اللغة الأجنبية لا يقتصر تعلمها داخل الفصل من خلال محتوى الدرس فحسب، بل تعلم من خلال الاحتكاك بالبيئة الخارجية المحيطة بالمتعلم.

فالطفل الأجنبي الذي يتعلم اللغة العربية في بيئة عربيى، يسهل عليه عملية التعلم التي تحدث داخل عالمه الصغير (المدرسة)، حيث تعمل البيئة اللغوية على زيادة خبراته اللغوية الجحديدة، وبتعله يطبق ما يتعلمه داخل الفصل في حياته العملية اليومية، الأمر الذي يؤكد أن نمو اللغة عنده واكتسابه اللغة مؤكد بقوة قانونه البيئة. كما يؤكد أن البيئة الخارجية يمكنها أن تقدم نموذجا كاملا للغة المراد تعلمها.

الخلاصة

من المباحث السابقة ظهرت أمامنا أهمية ودور البيئة اللغوة العربية في تعليم اللغة العربية لغير الناطقين بها. والبيئة اللغوية نفسها قد يتكون من البيئة الرسمية والبيئة غير الرسمية. كلتا من هذه البيئة تساعد في إبحاح تعليم اللغة العربية. وكل عملية التعليم والتدريس ما عقد في المدرسة لن يكن فعّال إذا لم يتحقق بوجود البيئة اللغوية العربية. لأن البيئة اللغوية العربية تحفظ اللغة المكتسبة لدي متعلم اللغة العربية بجميع أنشطتها ما تساعد على نمو وممارسة اللغة العربيةخاصة للدارسين غير الناطقين بها. ولكن هذه البيئة لا تستطيع أن تقوم بواجبتها إذا لم بحلس معها المعلم والمتعلم يي مسك نظام اللغة العربية. الممارسة بالقراءة والنطق والكتابة وكذلك بالمحادثة اليومية باستخدام اللغة المكتسبة أو اللغة العربية. إذا قامت جميع عناصر تعليم اللغة العربية بواجبتها على حفظ اللغة العربية وحفظ البيئة اللغوية العربية، فتكون كل متعلم اللغة العربية فاهما وقادرا على اللغة العربية لسانا وكتابة. 


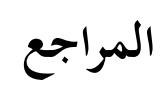

الخولي، محمد علي. أماليب تلدريس اللغة العربية. الأردن: دار الفلاح للنشر والتوزيع، .

الخولي، محمد علي. الحياة مع لغتين(الثنائية اللغوية). الرياض: جامعة املك السعود، 1480

السرطاوي، فؤاد عبد اللطيف البيئة والبعد الإسلامي عمان: دار المسيرة ، 1999

الفهري، عبد القادر الفاسي. اللغة والبيئة. سبريس: الدار البيضاء، 2003 م. بشيري. تكوين بيئة المساعلدة وتطويرها في تعليم اللغة العربية .مالانج: المقالة التي ألقاها في الدورة التدربية للمعلمين اللغة العربية جاوى - بالي، 2001 م. جميع الحقوق ملحوظة لحامعة المدينو العالمية ـ طرق تلدريس مواد اللغة العربية ـ طبعة الجامعة المدينة العالمية. 2011 م.

صباريني، رشيد الحميد ومحمد سعيد . البيئة ومشككلاتها ـ الكويت: عالم المعرفة ، 1979

طعيمة، رشدي أحمد ـ المهارات اللغوية مستوياتها تلدريسها صعوبتها ـالقاهرة: دار

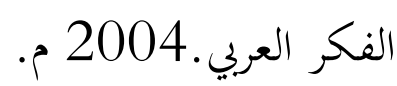

مدكور، علي أحمد تلدريس فنون اللغة العربية .القاهرة: دار الفكر العربي. 2006 


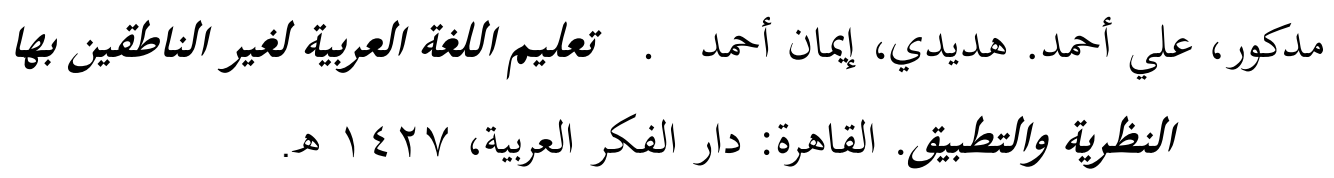

Chaer, Abdul. Psikolinguistik Kajian Teoritik. Jakarta: PT Rineka Cipta.2015.

Effendy, Ahmad Fuad. Metodologi Pengajaran Bahasa Arab. Malang: Misykat. 2005

Hadi, Nur. Dimensi-Dimensi Dalam Belajar Bahasa Kedua .Bandung: Sinar Baru.2007.

Hermawan, Acep Metodologi Pembelajaran Bahasa Arab, Bandung: Rosdakarya, 2011 